\title{
Early Number Competencies of Children at the Start of Formal Education
}

\author{
Eshun-Famiyeh, J. \\ Department of Mathematics Education, University of Education, Winneba
}

\begin{abstract}
In Ghana, like many other countries, mathematics is compulsory throughout the preuniversity period of education. However, a good proportion of pupils and students at basic secondary levels of education find the subject very difficult, while at the same time, those who profess not to be good in it take pleasure in doing so. The teaching and learning of mathematics have therefore been the concern of mathematics educators, teachers, parents and indeed all those who manage education. Addition and subtraction occupy a central position in the Primary Mathematics Curriculum in Ghana. The question then is: do pupils come to formal school without sufficient knowledge in counting and strategies for solving addition and subtraction problems? The focus of this study was to investigate pupils' counting strategies and how these influenced their procedures for solving addition and subtraction tasks at the start of formal school. A qualitative case study approach was adopted for the collection of data form BS1 pupils of two primary schools in Winneba. These pupils were just beginning their formal basic education in September. Findings from the two-site case study evidence were analysed for their significance. The results of the study suggest that pupils possess varied abilities and competencies in counting when they start formal school. The findings also revealed that pupils have and demonstrate a fair knowledge of addition and subtraction concepts. Another issue that came to light was the impact the socio-economic background of the home has on pupils' early number competence. Summary and conclusions of the study were based on the evidence of these findings.
\end{abstract}

\section{Introduction}

Mathematics exists all around us. It can be regarded as a science of number, patterns, quantity and space. It is widely regarded as one of the most important school subjects and a central aspect of the school curriculum in every society. It is the view of Orton and Frobisher (1996) that "more lessons of mathematics are taught in schools and colleges throughout the world than any other subject in the curriculum" (p. 1). In Ghana, the National Curriculum defines Mathematics, together with English Language and Science, as a core subject, and is compulsory for all learners up to Form 3 of the Senior Secondary School (SSS) at age 18. Orton and Frobisher (1996) also note that "whenever concerns are expressed about attainment of pupils in England and Wales and comparisons, whether legitimate or not, are made with pupils in other countries, mathematics is usually singled out as being a particularly worrying problem" (p. 1). In Ghana a lot of concern is frequently expressed about the low achievement in mathematics at both basic and secondary levels of education. Many other countries also share the same sentiments about performance in mathematics. This is revealed by the amount of research that has been and continues to be carried out in many countries with the view to improving the teaching and learning of the subject. It appears the whole world regards mathematics as a very important subject and expects that every child demonstrate a high level of attainment in the subject. The study of many disciplines/subjects depends on the knowledge, concepts and skills of mathematics. 
Mathematics, apart from the fact that it forms a major part of the school curriculum, also has a variety of applications in several fields of human endeavour. In everyday life for instance, both the schooled and the unschooled depend on mathematical knowledge and ideas for transactions in commerce, industry and business, as is demonstrated by, for example, the many contributions to Harris (1991). The schooled and the unschooled refer to those who have had formal education and those have not had formal education, respectively.

As a subject taught in school, the importance of Mathematics is also emphasised by the fact that it is expected that children who may seek for jobs and those hoping to have further education must demonstrate a certain degree of attainment. In Ghana many parents may expect their children to succeed in the subject, with the hope that job opportunities and further education and training will be enhanced. This is so because the minimum requirement for employment into any skilled job includes at least a pass in core mathematics at the Senior Secondary School (SSS) level. Also, a pass in core mathematics is a requirement for entry and pursuance of any course in any tertiary or higher institution. As a result, many students who perform very well in other subjects but fail to obtain a pass in core mathematics do not gain admission to higher education or employment into any skilled job. This is evident in the large numbers of students who register and re-sit core mathematics examination.

In Ghana, even teachers who may never teach any mathematics need to pass in core mathematics at the senior secondary school before being admitted into teacher training institutions. The assumption is also made frequently that for children to grow into adults, capable of solving the problems of science, life, and the world, their level of attainment in mathematics should be high.

Mathematics as a subject taught in school, generates in many pupils and students a feeling of fear, anxiety, unease and insecurity. Responses such as: 'if you teach mathematics then you must be very brilliant', 'I never liked mathematics at school', and 'oh no, not mathematics! I am very poor at it', are very common expressions of the way other people also feel about and perceive mathematics. Mathematics is held in high esteem to the point that those who perform well at it in school are thought to be very intelligent. While those who succeed are regarded as intelligent, Orton and Frobisher (1996) argue that "those who profess not to be any good at mathematics do so all too frequently and with pride" (p. 2). It is not beneficial for the future of children in this highly technological age if a section of society is happy about not being good at mathematics. It also reflects badly on school mathematics that many people appear to be content with their poor attainment in mathematics while in school. In Ghana even pupils in the basic education level (Upper Primary and Junior Secondary) express their fear and insecurity about mathematics. Results of Criterion Referenced Test for Primary Six pupils in mathematics revealed that the pupils had difficulty in learning the subject (MOE 1996). The harm that is inflicted, as many people take pleasure in their under-attainment in mathematics, takes a greater toll on girls (Orton and Frobisher 1996). In Ghana it appears many people do not expect girls to attain higher standards in mathematics, as very discouraging remarks are made about girls who perform very well in the subject. Orton and Frobisher (1996) further contend "if society needs a better mathematically educated adults, and if genuine equality of opportunity is to be provided, more girls need to be persuaded to consider studying mathematics for a longer period of time" (p. 3). Now, what does school mathematics entail that makes it appear so difficult to pupils? Or why do many people express so much anxiety and fear at the mention of 'mathematics'?

The answers to these and other related questions have been that either many teachers do not teach the subject properly for pupils to understand, or the curriculum for mathematics at the early stages of children's learning is too demanding. Yet, others think that children are not sufficiently developed or mature enough to learn mathematics, since they have to encounter lots of symbols and abstractions. The question of curriculum is always addressed by drawing up new curriculum and yet the concerns still persist. 
Teachers have repeatedly been criticised for the poor standards achieved by some pupils in mathematics in the primary school (Haylock and Cockburn 1997). For example, in Ghana when the results of the first batch of students of the Senior Secondary School (SSS) system showed a very poor output in 1993, the Minister of Education, in his comments on the results, blamed the poor performance on poor teaching and bad teaching. Whether or not these criticisms are justified, a laudable aim of teachers at the basic level of education is for all pupils to achieve the highest possible standards in mathematics and move on to higher classes with as much confidence and competence in this core subject as possible. To achieve this end, teachers surely have to recognise that they have a sound and thorough understanding of the basic characteristics, abilities and competencies that their pupils possess. The first few years of schooling are very vital for laying a foundation for understanding; there are mathematical concepts and skills taught in the lower primary years that will recur throughout a child's learning of mathematics.

From the previous section, mathematics is seen as a very important subject on the school curriculum and for entry into higher education or the world of work. However, many children who enter formal school with early number abilities and competencies soon grow to dislike mathematics. My own concerns have been agitated by the following questions:

- How do children come to hate mathematics?

- What mathematical ideas or competencies do children come to formal school with?

- Are teachers aware of the competencies children bring into formal school?

- These issues have bothered me for some time now. Answers to these questions, especially the second, form the basis of this study.

In primary schools in Ghana, especially in Basic Stages One and Two, addition and subtraction occupy a central position in the entire primary mathematics curriculum (MOE, 1998). Vergnaud (1982) argues that the concept of additive structure, of which simple addition and subtraction are most elementary examples, underlies a large portion of mathematics learnt in school and develops over an extended period of time. The transition from children's informal counting and modelling strategies developed inside or outside formal classroom instruction, to the use of memorised number facts and formal addition and subtraction algorithms according to Carpenter (1981) is a critical stage in children's learning of mathematics. Carpenter (1981) further contends that some children's later difficulty in mathematics can be traced back to initial instruction in addition and subtraction. Children's attitudes towards mathematics in general, may also depend to a large extent on the way addition and subtraction concepts are introduced to them at these early stages. Early experiences may be influential in determining children's attitude towards mathematics later on in life. Hence we need to understand children's early development of number and counting competencies as a prelude to the effective teaching of addition and subtraction. Nunes and Bryant (1996) point out, "addition and subtraction are quite complicated concepts, and until children grasp the conceptual basis of these operations they will be unable to use any procedures that are taught or any facts that they pick up at school" (p. 114).

According to Resnick and Ford (1981) when primary-age children are presented with basic addition and subtraction tasks, they tend to rely on informal counting strategies (i.e. strategies that have not been taught) to obtain their sums and differences, respectively. From my experience with young children as they solve addition and subtraction tasks, I have observed that some children count on their fingers, while others solve from known number facts or combinations, and others give immediate or spontaneous answers. I have also realised that some young children tend to make reversal errors when subtracting, in which case, they tend to subtract the smaller number from the larger number no matter the arrangement of the numbers. It is thus realised that some barriers exist to learning when children always rely on or use their informal strategies to solve addition and subtraction tasks. Difficulties also arise, if during the 'learning to count' process children learn to recite number words without 
reference to objects. This is referred to as rote learning. Such children may arrive in school able to string number words together even in their right sequence but may not have any understanding that the last number word describes the quantity of the set of objects counted.

Having realised that young children enter formal classroom with different backgrounds and capabilities in handling number, steps need to be taken, as early as possible, to develop positive attitudes to learning mathematics. One of the most effective ways of doing this is to find out the stages of development of children and the strategies they use with numbers (i.e. their counting schemes). When this has been done, teaching approaches could be designed to suit or meet each child's developmental level in order that they use more sophisticated schemes. Ausubel (1968) argues that the most important single factor that influences meaningful learning is indeed, what the learner already knows. Having knowledge of pupils' counting strategies and procedures for solving addition and subtraction tasks at the beginning of formal schooling may provide a useful starting point for teaching.

It is in the light of the above that this study is being undertaken to explore children's counting schemes and to investigate how these strategies are used in solving addition and subtraction tasks. The main focus of my study therefore, is to identify the counting strategies used by Ghanaian children and their use of counting for solving addition and subtraction tasks at the beginning of formal schooling.

Children differ in the counting schemes they possess and this may not only limit the development of the representation of addition and subtraction concepts, but may also affect the type of problems they can individually solve (Eshun 1985, Fuson 1988). Studies by Thealer (1981) have also indicated that even when children have been given common instruction there is still a significant difference in the strategies they use in solving addition and subtraction problems.

According to Ginsburg (1977) and Baroody and Ginsburg (1990), children assimilate school arithmetic into existing cognitive structures. Indeed Baroody and Ginsburg (1990) emphasise that

Children do not merely absorb or make a mental copy of new information; they assimilate it. That is, children filter and interpret new information in terms of their existing knowledge. Children ... cannot assimilate new information that is completely unfamiliar (p. 55).

Therefore, when given addition and subtraction tasks, children attempt to solve them according to the way they organise their experience at the level of development they find themselves. Results of Baroody and Ginsburg's (1990) studies reveal that there is the need to consider individual children's strengths and weaknesses when planning instruction for any group of children no matter how 'homogeneous' they may appear to be in age (i.e. even if they are of the same age group). Thus, in designing instruction with the view that all children in the class would understand, it is essential as Brownell (1928) re-echoes that "teachers be fully informed concerning the stages of development of the children by means of continuous study ... of the procedures and processes which the children employ in dealing with numbers" (p. 143). This means that it is important for teachers to find out first the level of development of their pupils, their counting skills and the strategies these pupils use in solving addition and subtraction tasks, before designing instruction to take care of their individual cognitive differences. The challenge to teachers of young children is to provide a carefully structured, activity-based curriculum, within a well-resourced environment, built around high teacher involvement and opportunities for children to learn together.

\section{Methodology}

Qualitative methods were adopted and used to collect data for the study. The main source of data for the study was pupils' clinical interviews. This was followed by observation during classroom teaching. The study sites were located in Winneba. In choosing the study site, I relied on purposeful sampling technique. The logic of purposeful sampling invariably differs 
from the logic of probability sampling in statistics. The choice of the study sites, the school and the pupils did not depend on any random and representative manipulations. The choice of the purposeful sampling technique rests on the desire to obtain information-rich cases for the study. Any of the primary schools in Winneba could have been selected for the study. I however, undertook the fieldwork with pupils of the Basic Stage One (BS1) classes in the Methodist C \& D Primary and University Practice Primary Schools.

This was a purposive sample. In qualitative research, participants (or settings, such as schools or organisations) are carefully selected for inclusion, based upon the possibility that each participant (or setting) will expand the variability of the sample (Maykut and Morehouse 1994). Purposive sampling increases the likelihood that variability common in any social phenomenon will be represented in the data, in contrast to random sampling which tries to achieve variation through the use of random selection and large sample size.

Basic Stage One (BS1) pupils, who were just beginning formal education in September, were clinically interviewed and thirty pupils from each school were selected for the writing up of the report. The pupils selected for the writing up of the study were those who demonstrated a better understanding of some unusual phenomenon or whose behaviours were particularly illuminating (Patton 1990). In sampling for qualitative research it is suggested that the most prominent and useful strategy is maximum variation sampling, where the researcher attempts to understand some phenomenon by seeking out persons or settings that represent the greatest differences in that phenomenon (Lincoln and Guba 1985).

The pupils were interviewed to get an insight into their counting strategies and how they used these strategies in solving addition and subtraction tasks, which involved the use of familiar materials. This occupied a major part of the fieldwork and was mainly to gather descriptive data in the participants own words and actions so that insights could be developed on how pupils' strategies. During the interviewing process, however, the pupils who were not comfortable with the activities were excused.

The tasks given to the participants involved counting of kernels in varying quantities and arrangements. Kernels are obtained from palm nuts when the outer fibre part is removed. Local children play various games with palm kernels because they are very common. The pupils also solved addition and subtraction tasks with some of the kernels screened. It should be acknowledged that as the interviewing progressed the pupils become more composed.

The pupils' clinical interviews were video-recorded since it involved the use of concrete materials, such as kernels. Maykut and Morehouse (1994) confirm that, "more recently, the use of video-tape has found a place among the collection of data gathering strategies available to researchers" (p. 112). The videotape allowed me to capture gestures, and other non-verbal actions, such as indicating acts used in counting, that were displayed by the pupils, but which were important to the study. The videotape also allowed me to view and re-view pupils' responses over and over again for further analysis.

\section{Results and Discussion}

The discussion brings together counting, addition and subtraction skills demonstrated by Basic Stage One pupils and views expressed by their teachers. These were analysed for their central themes and implications. The focus of this research was intended to find out the counting, addition and subtraction competence that pupils bring to formal school. With this in mind, pupils were asked to count a number of objects, ranging from four to nineteen, arranged in various forms on several trials. Also, activities that involved hidden objects were carried out to find out how pupils attempted to add and subtract small numbers. The data showed clearly that even though pupils are to start formal schooling at the age of six, there were pupils who were older than seven. The distribution of pupils and their ages is shown in Table 1. 